\title{
Current status of integrating oncology and palliative care in Japan: a nationwide survey
}

Y. Uneno ${ }^{1,2^{*}}$, K. Sato $^{3}$, T. Morita ${ }^{4}$, M. Nishimura ${ }^{5,6}$, S. Ito ${ }^{6}$, M. Mori ${ }^{7}$ C. Shimizu ${ }^{8}$, Y. Horie ${ }^{9}$, M. Hirakawa ${ }^{9}$,

T. E. Nakajima ${ }^{9}$, S. Tsuneto $^{10}$ and M. Muto ${ }^{1}$

\begin{abstract}
Background: Palliative care (PC) is increasingly recognized as essential for oncology care, and several academic societies strongly recommend integrating oncology and palliative care (IOP) in daily practice. Similarly, the Japanese government encouraged the implementation of IOP through the Cancer Control Act of 2007; however, its detailed progress remains unclear. Therefore, this cross-sectional nationwide survey was conducted to investigate the current status and hospital executive physicians' perception of IOP.
\end{abstract}

Methods: The questionnaire was developed based on IOP indicators with international consensus. It was distributed to executive physicians at all government-designated cancer hospitals (DCHs, $n=399)$ and matched non-DCHs $(n=478)$ in November 2017 and the results were compared.

Results: In total, 269 (67.4\%) DCHs and 259 (54.2\%) non-DCHs responded. The number of PC resources in DCHs was significantly higher than those in non-DCHs (e.g., full-time PC physicians and nurses, $52.8 \%$ vs. 14.0\%, $p<0.001$; availability of outpatient PC service $\geq 3$ days per week, $47.6 \%$ vs. $20.7 \%, p<0.001$ ). Routine symptom screening was more frequently performed in DCHs than in non-DCHs (65.1\% vs. $34.7 \%, p<0.001)$. Automatic trigger for PC referral availability was limited (e.g., referral using time trigger, $14.9 \%$ vs. $15.3 \%, p=0.700$ ). Education and research opportunities were seriously limited in both types of hospitals. Most executive physicians regarded IOP as beneficial for their patients $(95.9 \%$ vs. $94.7 \%, p=0.163)$ and were willing to facilitate an early referral to $P C$ services $(54.7 \%$ vs. $60.0 \%, p<0.569)$; however, the majority faced challenges to increase the number of full-time PC staff, and $<30 \%$ were planning to increase the staff members.

Conclusions: This survey highlighted a considerable number of IOP indicators met, particularly in DCHs probably due to the government policy. Further efforts are needed to address the serious research/educational gaps.

Keywords: Palliative care, Oncology, Care delivery, Quality improvement, Organizational innovation

\section{Background}

In the last decades, palliative care (PC) is widely recognized as an emerging clinical expertise and an essential part of oncology care [1,2]. Recent cumulative evidence revealed that early integration of $\mathrm{PC}$ is effective for patients with advanced cancer undergoing cancer treatment [3-5]. Several academic societies, including the

\footnotetext{
* Correspondence: yuuneno@kuhp.kyoto-u.ac.jp

${ }^{1}$ Department of Therapeutic Oncology, Graduate School of Medicine, Kyoto University, 54 Kawaharacho Shogoin Sakyo-ku, Kyoto 606-8507, Japan ${ }^{2}$ Seirei Hospice, Seirei Mikatahara General Hospital, Hamamatsu, Japan Full list of author information is available at the end of the article
}

European Society for Medical Oncology and American Society of Clinical Oncology, strongly support and recommend integrating oncology and palliative care (IOP) in daily oncology practice [6, 7].

Similarly, the Ministry of Health, Labor, and Welfare in Japan has been enhancing the early and continuous delivery of quality care for patients with cancer (both early and advanced stage) from the time point of cancer diagnosis via the Cancer Control Act since 2007 [8, 9]. The policy promotion includes comprehensive strategies including PC training for all physicians working at all governmentdesignated cancer hospitals (DCHs), implementation of

(c) The Author(s). 2020 Open Access This article is distributed under the terms of the Creative Commons Attribution 4.0 International License (http://creativecommons.org/licenses/by/4.0/), which permits unrestricted use, distribution, and 
PC services and routine screening, the establishment of referral criteria to PC services, and public education $[8,10-$ 13]. However, detailed progress and dissemination of IOP remain unclear.

Therefore, this cross-sectional nationwide survey aimed to investigate the current status and executive physicians' perception of IOP.

\section{Methods}

This cross-sectional nationwide survey in Japan was conducted targeting executive physicians at hospitals providing cancer treatments as respondents. The survey form was distributed in November 2017, and nonresponding institutions were reminded 3 weeks after the first mailing. Responses to the survey in written format were considered consent to participate. Based on the national ethical guideline of epidemiological studies in Japan, this study was exempted from review by the Ethics Committee at the Kyoto University Graduate School and Faculty of Medicine, Kyoto University Hospital.

\section{Target samples}

Two target samplings were identified: one was 399 DCHs, where the Ministry of Health, Labor, and Welfare-authorized high-quality cancer treatment was provided, and the other sample was non-DCHs that potentially manage patients with cancer because a considerable number of patients could receive cancer treatment at non-DCHs. Non-DCHs were randomly sampled and then stratified based on regions and inpatient bed numbers.

The sampling strategy is summarized in Fig. 1. To identify DCHs, the list of DCHs was obtained from the Ministry website as of April 2017. To identify nonDCHs, all hospital data were acquired from Japan Medical Press, Inc., in October 2017. To identify non-DCHs that offer cancer treatment, we excluded the following hospitals: (i) hospitals with $<100$ general ward beds (this was because there were no DCHs with $<100$ inpatients beds), (ii) national sanatorium, (iii) hospitals not delivering cancer treatment based on the hospital name and clinical departments (e.g., rehabilitation hospitals or no cancer treatment departments), and (iv) others (e.g., breast cancer-specified hospitals). To ensure representativeness and comparability between DCHs and nonDCHs at each region, stratified random sampling was performed based on the region and inpatient bed number. Regional strata were divided into nine categories: Hokkaido, Tohoku, Tokyo, Kanto other than Tokyo, Chubu, Kansai, Chugoku, Shikoku, and Kyushu-

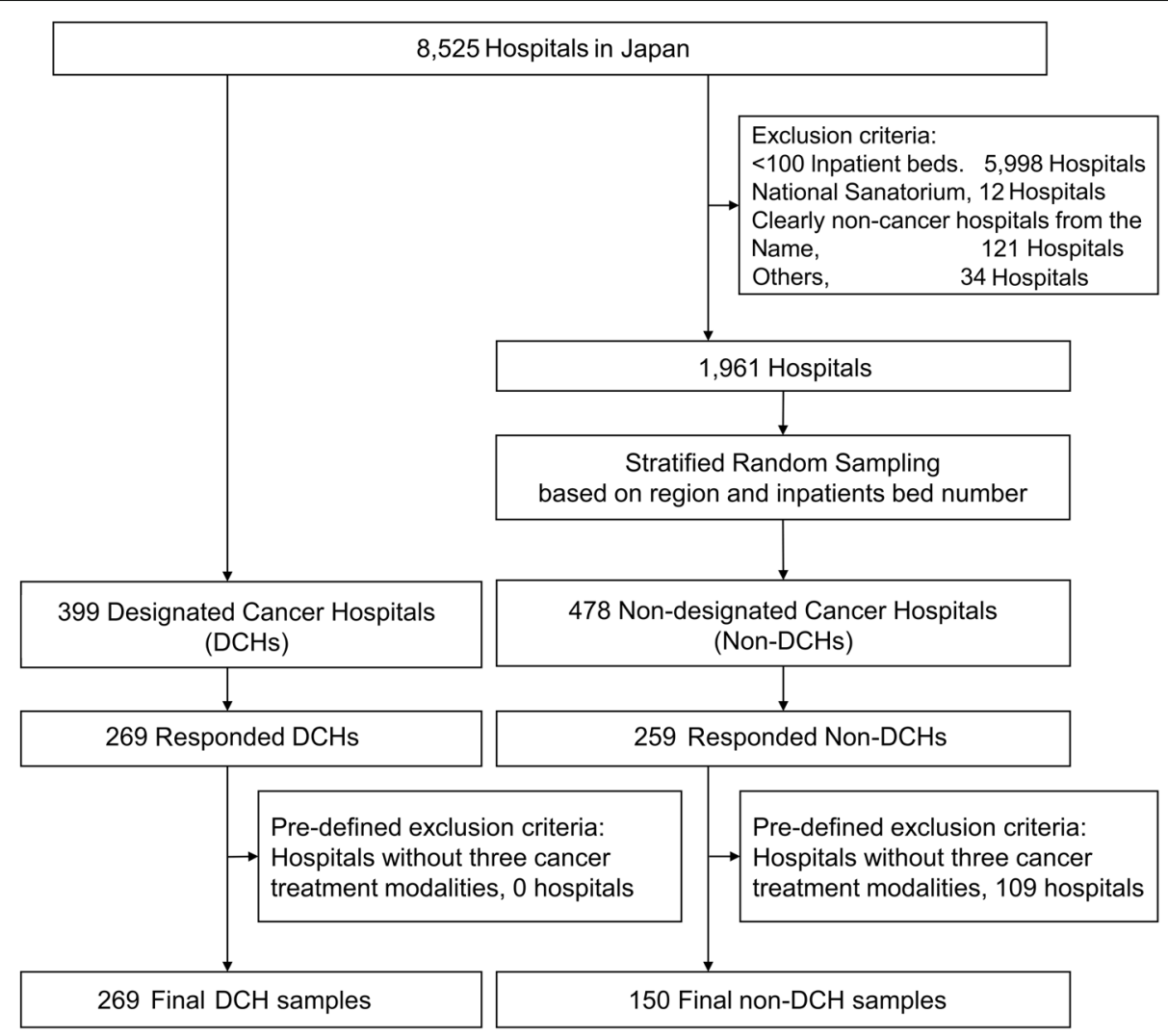

Fig. 1 Sampling diagram 
Okinawa. Inpatient bed number strata were divided into four categories based on the actual distribution of DCHs: $<299$ beds, 300-499 beds, 500-699 beds, and >700 beds. Considering the possibility that the response rate from non-DCHs may be low, three times more nonDCHs were extracted in each stratum. Moreover, responding hospitals that did not provide three cancer treatment modalities (surgery, systemic chemotherapy, and radiation therapy) at their own hospitals were excluded from the analysis in order to ensure comparability according to predefined exclusion criteria.

\section{Sample size calculation}

We did not define a primary outcome owning to the explanatory nature of the survey. However, to compute the confidence interval of the point estimate within $10 \%$, responses were needed from at least 96 hospitals. Therefore, at least $40 \%$ of responses were estimated to be obtained, consisting of 240 hospitals from both types of hospital.

\section{Survey development}

The questionnaire was created after a comprehensive literature search. A pilot test was performed on three physicians with positions equivalent to that of executives in cancer hospitals to ensure face and content validity.

\section{i) Current status of IOP}

To clarify the current status of IOP, the international consensus was used as the IOP indicator [14], consisting of five sections: clinical structure, clinical process, clinical outcomes, education, and research, which were categorized as major or minor indicators. Clinical outcome indicators were excluded because the target respondents were experiencing difficulties in answering these questions due to the heterogeneity among specialties within the same hospitals based on the pilot test results. Thus, a total of 25 questions (Tables 2, 3, 4) were primarily used based on the categorical answer format from no (0\%), limited (1-24\%), approximately half (25-74\%), mostly (75-99\%), and all (100\%) departments.

\section{ii) Executive physicians' perception toward IOP}

To investigate executive physicians' perceptions of the oncology department toward IOP, 16 questions were used based on the literature search $[6,15-21]$. Each question was rated on a 5-point Likert-type scale, from 1 (strongly disagree) to 5 (strongly agree). In addition, a free text query was prepared by asking opinions regarding IOP.

\section{Analysis}

Descriptive statistics was performed to summarize the data. To adjust the biased distribution of inpatient bed number between the responding DCHs and non-DCHs, each stratum of non-DCHs was weighted according to $\mathrm{DCH}$ distributions in inpatient bed number $(<299$ beds, 300-499 beds, 500-699 beds, and $>700$ beds). Missing data was not imputed. The t-test or Cochrane-Armitage trend test was used to compute differences in the proportion, as appropriate. A $P$-value of $<0.05$ was considered statistically significant. Owning to the exploratory nature of this survey, the adjustment of multiple testing was not performed. The GNU R software (version 3.2.0; R Project for Statistical Computing, Vienna, Austria) was used for all statistical analyses.

Free comment responses were qualitatively analyzed using inductive content analysis method [22, 23]. Two independent investigators (M.N. and S.I.) reviewed and generated the codes. Then, emerging codes were compared and discussed with an expert PC physician (Y.U.) to achieve agreement of the codes labeled from the data. To ensure rigor and trustworthiness, an experienced investigator (T.M) supervised and examined the consistency of results.

\section{Results}

\section{Response rates and demographic data}

Among the 399 DCHs and 478 non-DCHs surveyed, a total of $269(67.4 \%)$ and $259(54.2 \%)$ responded, respectively. Among the latter, 150 non-DCHs (31.4\%) were included for analyses where surgery, chemotherapy, and radiation therapy were performed within the same hospitals to ensure comparability. The hospital's demographic data are summarized in Table 1.

\section{Major IOP indicators (Table 2)}

More than $90 \%$ of the DCHs had full-time PC staff (91.5\% vs. $42.0 \%$ ), interdisciplinary PC team (a team of two or more occupations) $(98.5 \%$ vs. $90.0 \%)$, and outpatient clinics $(95.2 \%$ vs. $58.0 \%)$, and the rates were significantly higher than that in non-DCHs. Routine symptom screening was performed in more than half of the DCHs (65.1\% vs. 34.7\%); however, routine documentation of advanced care planning was performed in < $40 \%$ in both types of hospitals (39.0\% vs. $28.7 \%)$. Automatic trigger for PC referral was also employed in $<40 \%$ of surveyed hospitals (time trigger, $14.9 \%$ vs. $15.3 \%$; needs trigger, $37.5 \%$ vs. $27.3 \%$ ).

\section{Minor IOP indicators (Table 3)}

Symptom management guidelines (88.9\% vs. $78.7 \%)$ and PC referral criteria (71.7\% vs. $58.7 \%)$ were well equipped in both types of hospitals. Concurrent services between oncology and PC were available in more than $95 \%$ of 
Table 1 Characteristics of responding hospitals

\begin{tabular}{|c|c|c|c|c|c|c|}
\hline & \multicolumn{3}{|l|}{ Unmatched } & \multicolumn{3}{|l|}{ Matched } \\
\hline & $\begin{array}{l}\text { Designated Cancer } \\
\text { Hospitals }(n=269)\end{array}$ & $\begin{array}{l}\text { Non-Designated } \\
\text { Cancer Hospitals } \\
(n=150)\end{array}$ & $P$-value & $\begin{array}{l}\text { Designated Cancer } \\
\text { Hospitals }(n=269)\end{array}$ & $\begin{array}{l}\text { Non-Designated Cancer } \\
\text { Hospitals }(n=150)\end{array}$ & $\begin{array}{l}\text { Adjusted } \\
P \text {-value }\end{array}$ \\
\hline & n (\%) & n (\%) & & n (\%) & n (\%) & \\
\hline Inpatient beds number & & & $<.0001$ & & & 0.998 \\
\hline 100-299 beds & $16(5.9)$ & $8(5.3)$ & & $14.2(5.3)$ & $7.9(5.3)$ & \\
\hline 300-499 beds & $95(35.3)$ & $115(76.7)$ & & $96.4(35.8)$ & $53.7(35.8)$ & \\
\hline $500-699$ beds & $107(39.8)$ & $23(15.3)$ & & $101.1(37.6)$ & $56.4(37.6)$ & \\
\hline 700 beds & $51(19.0)$ & $4(2.7)$ & & $57.3(21.3)$ & $32.0(21.3)$ & \\
\hline \multicolumn{7}{|l|}{ Activities of responding institutions ${ }^{\mathrm{a} 1}$} \\
\hline Inpatient beds available & $555.6[197.8]$ & $414.7[131.7]$ & $<.0001$ & 563.8 [202.8] & 547.5 [234.6] & 0.457 \\
\hline Annual number of cancer death & $233.3[158.8]$ & $147.4[119.1]$ & $<.0001$ & $234.2[158.5]$ & $201.7[190.4]$ & 0.078 \\
\hline
\end{tabular}

hospitals (97.8\% vs. $96.7 \%)$, and more than half of them $(86.3 \%$ vs. $53.3 \%)$ involved the PC staff in the multidisciplinary tumor conference. With regard to prompt PC service delivery, both types of hospitals tend to have less capacity in outpatient setting compared to inpatient settings (inpatient settings, $93.7 \%$ vs. $73.3 \%$; outpatient settings, $78.8 \%$ vs. $60.7 \%)$.

\section{Education and research IOP indicators (Table 4)}

Education opportunity of PC for oncologists was limited in both types of hospitals (e.g., routine rotation in PC, $8.2 \%$ vs. $2.0 \%$ ); and education opportunity on oncology for PC physicians was also limited (e.g., routine rotation in oncology, $9.7 \%$ vs. $1.3 \%$ ). Research opportunity was more frequent in DCHs, but still far limited in both types of hospitals (e.g., tenured faculty in PC, 3.3\% vs. $1.3 \%)$.

\section{Executive physicians' perspectives toward IOP (Additional file 1)}

A total of $\geq 70 \%$ executive physicians in both types of hospitals did not regard their primary PC (PC services which was provided by the primary physicians and nurses) as good enough (74.7\% vs. $75.3 \%)$. They also indicated that IOP encouragement would be beneficial for their patients (95.9\% vs. $94.7 \%)$ and not be costly for their hospitals (29.4\% vs. $33.3 \%)$. However, many hospitals were facing challenges to allocate more staff to provide PC services $(75.5 \%$ vs. $86.7 \%)$. More than half of hospitals were planning to facilitate early referral to PC services (54.6\% vs. $60.0 \%)$.

\section{Qualitative analysis of free text query}

In total, 106 (26.6\%) DCHs and 68 (14.2\%) non-DCHs responded to the free text query. Summarized data is presented in Additional files 2, 3 and 4. Three major categories were generated: perception toward IOP, challenges to encourage IOP, and solutions to encourage IOP. The typical perception was that enhancing the primary PC service is vital due to the large estimated number of patients with PC needs as compared with the available specialized PC service, although the importance of IOP, in general, was recognized.

\section{Discussion}

This nationwide survey comprehensively investigated the current status and executive physicians' perspectives of IOP in Japan. From 2007, the Ministry of Health, Labor, and Welfare has presented several mandatory requirements for DCH certification, such as referral criteria for PC services, institutionally accepted symptom management guidelines, and routine PC screening, and many of these requirements overlapped with the surveyed IOP indicators. Thus, the current IOP status at DCHs was found to be highly satisfied with respect to the clinical structure and process indicators even as compared with the previous literature in the European and North American countries [6, 15, 17-20]. For instance, outpatient PC service availability was equivalent to European Society for Medical Oncology (ESMO)-designated centers (DCs) (e.g., Japan DCHs vs. ESMO DCs: outpatient clinic available $95 \%$ vs. $89 \%$; same-day outpatient consultation available, $79 \%$ vs. $82 \%$ ) [6]. This supported the promising role of the government to disseminate quality care nationwide.

Our survey also found that research and education opportunities were seriously limited at the vast majority of cancer hospitals. Continuing education for attending physicians was held in more than half of the facilities in ESMO DCs, whereas more than half of Japanese hospitals did not have opportunities for continuing education [6]. Mutual rotation training opportunities for fellows were also limited between oncology and PC departments. Research infrastructure was also extremely limited, with 
Table 2 Current status of major indicators in the integration of oncology and palliative care programs in Japan

\begin{tabular}{|c|c|c|c|c|}
\hline & \multirow{2}{*}{$\begin{array}{l}\text { Designated Cancer } \\
\text { Hospitals }(n=269) \\
\text { n (\%) }\end{array}$} & $\begin{array}{l}\text { Non-Designated } \\
\text { Cancer Hospitals } \\
(n=150)\end{array}$ & \multirow[t]{2}{*}{$P$ value } & \multirow[t]{2}{*}{$\begin{array}{l}\text { Adjusted } \\
P \text { value }\end{array}$} \\
\hline & & n (\%) & & \\
\hline \multicolumn{5}{|l|}{ Clinical structure } \\
\hline Presence of palliative care inpatient consultation team & & & $<0.001$ & $<0.001$ \\
\hline involving full-time both physicians and nurses & $142(52.8)$ & $21(14.0)$ & & \\
\hline involving full-time physicians only & $1(0.4)$ & $5(3.3)$ & & \\
\hline involving full-time nurses only & $103(38.3)$ & $37(24.7)$ & & \\
\hline involving part-time both physicians and nurses & $17(6.3)$ & $68(45.3)$ & & \\
\hline not available & $1(0.4)$ & $17(11.3)$ & & \\
\hline Presence of palliative care outpatient clinic & & & $<0.001$ & $<0.001$ \\
\hline available $\geq 5$ days a week & $85(31.6)$ & $16(10.7)$ & & \\
\hline available $3-4$ days a week & $43(16.0)$ & $15(10.0)$ & & \\
\hline available $<1-2$ days a week & $128(47.6)$ & $56(37.3)$ & & \\
\hline not available & $7(2.6)$ & $60(40.0)$ & & \\
\hline \multicolumn{5}{|l|}{ Clinical process } \\
\hline Presence of interdisciplinary palliative care team ${ }^{\mathrm{a} 1}$ & $265(98.5)$ & $135(90.0)$ & $<0.001$ & 0.015 \\
\hline \multicolumn{5}{|l|}{ Members of palliative care team } \\
\hline Pain clinicians or anesthesiologists & $117(43.5)$ & $40(26.7)$ & $<0.001$ & 0.024 \\
\hline Palliative care physicians expecting pain clinicians or anesthesiologists & $225(83.6)$ & $122(81.3)$ & 0.61 & 0.208 \\
\hline Palliative care nurses & $265(98.5)$ & $132(88.0)$ & $<0.001$ & $<0.001$ \\
\hline $\begin{array}{l}\text { Healthcare professionals treating psychological issues (e.g., psychotherapist, psychiatrist, } \\
\text { chaplain, or social worker) }\end{array}$ & $247(91.8)$ & $100(66.7)$ & $<0.001$ & $<0.001$ \\
\hline Medical social workers & $215(79.9)$ & $93(62.0)$ & $<0.001$ & 0.008 \\
\hline Nutritionists & $181(67.2)$ & $88(58.7)$ & 0.085 & 0.435 \\
\hline Pharmacists & $259(96.3)$ & $133(88.7)$ & 0.001 & 0.024 \\
\hline Others & $100(37.2)$ & $40(26.7)$ & 0.031 & 0.028 \\
\hline Routine symptom screening in the outpatient oncology clinic & & & $<0.001$ & 0.003 \\
\hline All departments (100\%) & $78(29.0)$ & $21(14.0)$ & & \\
\hline Most departments (75-99\%) & $62(23.0)$ & $21(14.0)$ & & \\
\hline Approximately half departments (25-74\%) & $35(13.0)$ & $10(6.7)$ & & \\
\hline Limited departments (1-24\%) & $71(26.4)$ & $41(27.3)$ & & \\
\hline No department (0\%) & $19(7.1)$ & $53(35.3)$ & & \\
\hline Routine documentation of advance care plans in patients with advanced cancer & & & 0.050 & 0.183 \\
\hline All departments (100\%) & $40(14.9)$ & $17(11.3)$ & & \\
\hline Most departments (75-99\%) & $42(15.6)$ & $14(9.3)$ & & \\
\hline Approximately half departments (25-74\%) & $23(8.6)$ & $12(8.0)$ & & \\
\hline Limited departments (1-24\%) & $47(17.5)$ & $31(20.7)$ & & \\
\hline No department (0\%) & $111(41.3)$ & $71(47.3)$ & & \\
\hline \multicolumn{3}{|l|}{ Early referral to palliative care using time trigger (e.g., 3 months after the diagnosis of incurability) } & 0.700 & 0.358 \\
\hline All departments (100\%) & $12(4.5)$ & $7(4.7)$ & & \\
\hline Most departments (75-99\%) & $13(4.8)$ & $5(3.3)$ & & \\
\hline Approximately half departments (25-74\%) & $15(5.6)$ & $8(5.3)$ & & \\
\hline Limited departments (1-24\%) & $26(9.7)$ & $14(9.3)$ & & \\
\hline No department (0\%) & $199(74.0)$ & $113(75.3)$ & & \\
\hline
\end{tabular}


Table 2 Current status of major indicators in the integration of oncology and palliative care programs in Japan (Continued)

\begin{tabular}{lll}
\hline & $\begin{array}{l}\text { Designated Cancer } \\
\text { Hospitals }(n=269)\end{array}$ & $\begin{array}{l}\text { Non-Designated } \begin{array}{l}P \text { value } \\
(n=150) \\
(\text { Adjusted }\end{array} \\
P \text { value }\end{array}$ \\
\hline Early referral to palliative care using needs trigger (e.g., pain with NRS $\geq 7)$ & $\mathrm{n}(\%)$ & 0.030 \\
All departments (100\%) & & 0.820 \\
Most departments (75-99\%) & $49(18.2)$ & $19(12.7)$ \\
Approximately half departments (25-74\%) & $35(13.0)$ & $10(6.7)$ \\
Limited departments (1-24\%) & $18(6.7)$ & $12(8.0)$ \\
No department (0\%) & $20(7.4)$ & $16(10.7)$ \\
\hline
\end{tabular}

${ }^{\mathrm{a}} 1$, a team of two or more occupations

levels similar to those in the USA in 2010 [15] (e.g., institutional funding for palliative oncology research, $19 \%$ in Japan vs. $13 \%$ in the USA). As education and research activities across the specialty can promote smooth coordination among healthcare professionals [24-26], further efforts to develop education and research infrastructures (e.g. employing tenured or full-time PC faculty who engages the education and research) are valuable.

Most leaders in cancer hospitals recognized IOP as beneficial and reasonable for their cancer patients. They also planned to facilitate early referral of cancer patients to PC services. Meanwhile, they were facing challenges

Table 3 Current status of minor indicators in the integration of oncology and palliative care programs in Japan

\begin{tabular}{|c|c|c|c|c|}
\hline & $\begin{array}{l}\text { Designated Cancer } \\
\text { Hospitals }(n=269)\end{array}$ & $\begin{array}{l}\text { Non-Designated Cancer } \\
\text { Hospitals }(n=150)\end{array}$ & $P$-value & $\begin{array}{l}\text { Adjusted } \\
P \text {-value }\end{array}$ \\
\hline & n (\%) & n (\%) & & \\
\hline \multicolumn{5}{|l|}{ Clinical Process } \\
\hline $\begin{array}{l}\text { Institutionally accepted palliative care symptom management guidelines in } \\
\text { written format }\end{array}$ & $239(88.9)$ & $118(78.7)$ & 0.004 & 0.238 \\
\hline Institutionally accepted palliative care referral criteria available in written format & $193(71.7)$ & $88(58.7)$ & $<0.001$ & 0.077 \\
\hline $\begin{array}{l}\text { Available institutionally accepted clinical care pathways (automatic triggers) for } \\
\text { palliative care referral }\end{array}$ & $47(17.8)$ & $8(5.3)$ & $<0.001$ & $<0.001$ \\
\hline \multicolumn{5}{|c|}{ Palliative care team routinely involved in multidisciplinary tumor conference for patient case discussions } \\
\hline Attending always & $128(47.6)$ & $38(25.3)$ & $<0.001$ & $<0.001$ \\
\hline Attending when necessary & $104(38.7)$ & $42(28.0)$ & & \\
\hline Not attending & $32(11.9)$ & $22(14.7)$ & & \\
\hline Multidisciplinary tumor conference is not held/no palliative care team & $3(1.1)$ & $46(30.7)$ & & \\
\hline $\begin{array}{l}\text { Presence of palliative care specialists among cancer center senior leadership (e.g., } \\
\text { head of oncology department/division and chief executives) }\end{array}$ & $103(38.3)$ & $44(29.3)$ & $<0.001$ & 0.052 \\
\hline $\begin{array}{l}\text { Administration of systemic cancer therapy (e.g., chemotherapy and targeted } \\
\text { agents) in palliative care patients possible }\end{array}$ & $263(97.8)$ & $145(96.7)$ & 0.115 & 0.262 \\
\hline \multicolumn{5}{|l|}{ Availability of the same-day inpatient palliative care consultation upon request } \\
\hline Almost all ( $\geq 90 \%)$ & $192(71.4)$ & $69(46.0)$ & $<0.001$ & $<0.001$ \\
\hline Mostly (50-89\%) & $60(22.3)$ & $41(27.3)$ & & \\
\hline Less likely (<49\%) & $14(5.2)$ & $28(18.7)$ & & \\
\hline Not available & $0(0.0)$ & $12(8.0)$ & & \\
\hline \multicolumn{5}{|l|}{ Availability of same-day outpatient palliative care consultation upon request } \\
\hline Almost all ( $\geq 90 \%)$ & $140(52.0)$ & $42(28.0)$ & $<0.001$ & $<0.001$ \\
\hline Mostly (50-89\%) & $72(26.8)$ & $49(32.7)$ & & \\
\hline Less likely $(<49 \%)$ & $52(19.3)$ & $35(23.3)$ & & \\
\hline Not available & $2(0.7)$ & $23(15.3)$ & & \\
\hline
\end{tabular}


Table 4 Current status of education and research indicators in the integration of oncology and palliative care programs in Japan

\begin{tabular}{|c|c|c|c|c|}
\hline & $\begin{array}{l}\text { Designated Cancer } \\
\text { Hospitals }(n=269)\end{array}$ & $\begin{array}{l}\text { Non-Designated Cancer } \\
\text { Hospitals }(n=150)\end{array}$ & $P$-value & $\begin{array}{l}\text { Adjusted } \\
P \text {-value }\end{array}$ \\
\hline & n (\%) & n (\%) & & \\
\hline \multicolumn{5}{|l|}{ Education, major indicators } \\
\hline Didactic palliative care curriculum for oncology fellows & & & $<0.001$ & 0.195 \\
\hline$\geq 50 \%$ fellows attend & $63(23.4)$ & $14(9.3)$ & & \\
\hline$<50 \%$ fellows attend & $78(29.0)$ & $39(26.0)$ & & \\
\hline Not available for the palliative care education & $124(46.1)$ & $95(63.3)$ & & \\
\hline Oncology fellows have routine rotation in palliative care & & & 0.007 & 0.224 \\
\hline$\geq 50 \%$ fellows have & $22(8.2)$ & $3(2.0)$ & & \\
\hline$<50 \%$ fellows have & $26(9.7)$ & $12(8.0)$ & & \\
\hline Not available for the palliative care education & $217(80.7)$ & $133(88.7)$ & & \\
\hline \multicolumn{2}{|l|}{ Combined palliative care and oncology educational activities for fellows/trainees } & & 0.002 & 0.394 \\
\hline$\geq 50 \%$ fellows/trainees attend & $20(7.4)$ & $6(4.0)$ & & \\
\hline$<50 \%$ fellows/trainees attend & $69(25.7)$ & $25(16.7)$ & & \\
\hline Not available for the palliative care education & $174(64.7)$ & $117(78.0)$ & & \\
\hline Continuing medical education in palliative care for attending oncologists & & & 0.002 & 0.260 \\
\hline$\geq 50 \%$ attending oncologists attend & $28(10.4)$ & $7(4.7)$ & & \\
\hline$<50 \%$ attending oncologists attend & $108(40.1)$ & $47(31.3)$ & & \\
\hline Not available for the palliative care education & $129(48.0)$ & $94(62.7)$ & & \\
\hline \multicolumn{5}{|l|}{ Education, minor indicators } \\
\hline Palliative care fellows have routine rotation in oncology & & & $<0.001$ & 0.011 \\
\hline$\geq 50 \%$ fellows attend & $26(9.7)$ & $2(1.3)$ & & \\
\hline$<50 \%$ fellows attend & $20(7.4)$ & $10(6.7)$ & & \\
\hline Not available for the palliative care education & $220(81.8)$ & $137(91.3)$ & & \\
\hline Continuing medical education in oncology for palliative care specialists & & & 0.003 & 0.376 \\
\hline$\geq 50 \%$ specialists attend & $36(13.4)$ & $12(8.0)$ & & \\
\hline$<50 \%$ specialists attend & $34(12.6)$ & $11(7.3)$ & & \\
\hline Not available for the palliative care education & $197(73.2)$ & $126(84.0)$ & & \\
\hline \multicolumn{5}{|l|}{ Research } \\
\hline Institutional funding for palliative oncology research & $50(18.6)$ & $11(7.3)$ & 0.002 & 0.039 \\
\hline Peer-reviewed publications in palliative oncology & $58(21.6)$ & $18(12.0)$ & 0.015 & 0.052 \\
\hline Tenured faculty in palliative care & $9(3.3)$ & $2(1.3)$ & 0.213 & 0.312 \\
\hline Collaborative research between oncology and palliative care & $29(10.8)$ & $13(8.7)$ & 0.467 & 0.858 \\
\hline
\end{tabular}

in recruiting specialized PC staff and less likely planned to employ more PC staff. Accordingly, the current specialized PC staff seemed to be overwhelmed by the routine clinical practice and had actual difficulties to implement more IOPs. Lack of PC resources is a wellknown barrier for IOP, and our qualitative analysis also supported this situation [27-29]. Given that enrichment of PC resources is unrealistic, enhancing the primary PC provided by oncologists to effectively optimize existing resources such as standardized care pathway may be valuable [1].
This study had several limitations. First, as target respondents were executive physicians in oncology departments, it was not evident whether several IOP indicators actually work in routine practice. Detailed analysis of how those indicators work in practice would help determine the optimal clinical IOP models. Second, as the target hospitals were restricted to those providing three cancer treatment modalities (i.e., surgery, radiation therapy, and chemotherapy), the results in these analyses cannot be generalized in smaller hospitals. Third, owning to the exploratory 
nature of the study, multiple tests were not adjusted which could limit the implications of the detected significant differences.

\section{Conclusions}

This survey highlighted that a considerable number of IOP indicators were satisfied in DCHs in Japan. Further investigation is warranted to clarify whether these indicators effectively work in achieving real clinical situations.

\section{Supplementary information}

Supplementary information accompanies this paper at https://doi.org/10. 1186/s12904-020-0515-5.

Additional file 1: TableS1. Perception of the integration of oncology and palliative care programs in Japan

Additional file 2: TableS2. Qualitative analysis of opinions toward the integration of oncology and palliative care

Additional file 3: TableS3. Challenges to encourage IOP

Additional file 4: TableS4. Solutions to encourage IOP

\section{Abbreviations}

DC: Designated center; DCH: Government-designated cancer hospital; ESMO: European Society for Medical Oncology; IOP: Integrating oncology and palliative care; PC: Palliative care

\section{Acknowledgements}

We sincerely appreciate the respondents' participation in this survey. Similarly, we would like to extend our appreciation to our department staff and to Shin-Jyoho Center for their diligent support during the survey process.

\section{Authors' contributions}

All authors (YU, KS, TM, MN, SI, MM, CS, YH, MH, TEN, ST, and MM) contributed to the study conception and design. Material preparation, data collection and analysis were performed by YU, KS, TM, MN and SI. The first draft of the manuscript was written by $Y U$ and all authors (YU, KS, TM, MN, $\mathrm{SI}, \mathrm{MM}, \mathrm{CS}, \mathrm{YH}, \mathrm{MH}, \mathrm{TEN}, \mathrm{ST}$, and MM) commented on previous versions of the manuscript. All authors (YU, KS, TM, MN, SI, MM, CS, YH, MH, TEN, ST, and MM) read and approved the final manuscript.

\section{Funding}

This work was supported the Ministry of Health, Labor, and Welfare in Japan (Health Labor Science Research Grant). The funder provided no role within conception or design of the work, the acquisition, analysis, interpretation of data and drafting manuscript.

\section{Availability of data and materials}

The datasets used and/or analysed during the current study are available from the corresponding author on reasonable request.

\section{Ethics approval and consent to participate}

Based on the national ethical guideline of epidemiological studies in Japan, this study was exempted from review by the Ethics Committee at the Kyoto University Graduate School and Faculty of Medicine, Kyoto University Hospital. Responses to the survey in written format were considered consent to participate.

\section{Consent for publication}

Not applicable.

\section{Competing interests}

Dr. Chikako Shimizu received a research fund from Eli Lilly Japan K.K. All remaining authors have declared no conflicts of interest.

\section{Author details}

'Department of Therapeutic Oncology, Graduate School of Medicine, Kyoto University, 54 Kawaharacho Shogoin Sakyo-ku, Kyoto 606-8507, Japan. ${ }^{2}$ Seirei Hospice, Seirei Mikatahara General Hospital, Hamamatsu, Japan. ${ }^{3}$ Department of Nursing, Nagoya University Graduate School of Medicine, Nagoya, Japan. ${ }^{4}$ Division of Supportive and Palliative Care, Seirei Mikatahara General Hospital, Hamamatsu, Japan. ${ }^{5}$ Geriatric Health Service Facility, You-You no Sono, Hiroshima, Japan. ${ }^{6}$ Department of Health Informatics, Kyoto University Graduate School of Medicine/ School of Public Health, Kyoto, Japan.

${ }^{7}$ Palliative Care Team, Seirei Mikatahara General Hospital, Hamamatsu, Japan. ${ }^{8}$ Department of Breast Medical Oncology, National Center for Global Health and Medicine, Tokyo, Japan. ${ }^{9}$ Department of Clinical Oncology, St Marianna University School of Medicine, Kawasaki, Japan. ${ }^{10}$ Department of Human Health Sciences, Graduate School of Medicine, Kyoto University, Kyoto, Japan.

Received: 26 October 2019 Accepted: 13 January 2020

Published online: 24 January 2020

\section{References}

1. Kaasa S, Loge JH, Aapro M, et al. Integration of oncology and palliative care: a lancet oncology commission. Lancet Oncol. 2018;19:e588-653.

2. Jordan K, Aapro M, Kaasa S, et al. European Society for Medical Oncology (ESMO) position paper on supportive and palliative care. Ann Oncol. 2018; 29:36-43.

3. Haun MW, Estel S, Rucker G, et al. Early palliative care for adults with advanced cancer. Cochrane Database Syst Rev. 2017:6:Cd011129.

4. Temel JS, Greer JA, El-Jawahri A, et al. Effects of early integrated palliative care in patients with lung and Gl cancer: a randomized clinical trial. J Clinical Oncol. 2017:35:834-41.

5. Vanbutsele G, Pardon K, Van Belle $\mathrm{S}$, et al. Effect of early and systematic integration of palliative care in patients with advanced cancer: a randomised controlled trial. Lancet Oncol. 2018;19:394-404.

6. Hui D, Cherny N, Latino N, Strasser F. The 'critical mass' survey of palliative care programme at ESMO designated centres of integrated oncology and palliative care. Ann Oncol. 2017;28:2057-66.

7. Ferrell BR, Temel JS, Temin S, et al. Integration of palliative care into standard oncology care: American Society of Clinical Oncology clinical practice guideline update. J Clin Oncol. 2017;35:96-112.

8. Morita T, Kizawa Y. Palliative care in Japan: a review focusing on care delivery system. Curr Opin Support Palliat Care. 2013;7:207-15.

9. Morita T, Miyashita M, Tsuneto S, Shima Y. Palliative care in Japan: shifting from the stage of disease to the intensity of suffering. J Pain Symptom Manag. 2008;36:e6-7.

10. Maeda I, Tsuneto S, Miyashita M, et al. Progressive development and enhancement of palliative care services in Japan: nationwide surveys of designated cancer care hospitals for three consecutive years. J Pain Symptom Manag. 2014;48:364-73.

11. Yamaguchi T, Narita M, Morita T, Kizawa Y, Matoba M. Recent developments in the management of cancer pain in Japan: education, clinical guidelines and basic research. Jpn J Clin Oncol. 2012;42:1120-7.

12. Okuyama T, Kizawa Y, Morita T, et al. Current status of distress screening in designated cancer hospitals: a cross-sectional nationwide survey in Japan. J Natl Compr Cancer Netw. 2016;14:1098-104.

13. Nakazawa $Y$, Yamamoto $R$, Kato $M$, et al. Improved knowledge of and difficulties in palliative care among physicians during 2008 and 2015 in Japan: association with a nationwide palliative care education program. Cancer. 2018;124:626-35.

14. Hui D, Bansal S, Strasser F, et al. Indicators of integration of oncology and palliative care programs: an international consensus. Ann Oncol. 2015;26:1953-9.

15. Hui D, Elsayem A, De la Cruz M, et al. Availability and integration of palliative care at US cancer centers. JAMA. 2010:303:1054-61.

16. Zagonel V, Torta R, Franciosi V, et al. Early integration of palliative care in oncology practice: results of the Italian Association of Medical Oncology (AIOM) survey. J Cancer. 2016;7:1968-78.

17. Berendt J, Stiel S, Nauck F, Ostgathe C. Early palliative care: current status of integration within German comprehensive cancer centers. Support Care Cancer. 2017:25:2577-80.

18. Davis MP, Strasser F, Cherny N. How well is palliative care integrated into cancer care? A MASCC, ESMO, and EAPC Project. Support Care Cancer. 2015; 23:2677-85. 
19. Davis MP, Strasser F, Cherny N, Levan N. MASCC/ESMO/EAPC survey of palliative programs. Support Care Cancer. 2015;23:1951-68.

20. Hammer SL, Clark K, Grant M, Loscalzo MJ. Seventeen years of progress for supportive care services: a resurvey of National Cancer Institute-designated comprehensive cancer centers. Palliat Support Care. 2015;13:917-25.

21. Friedrichsdorf SJ, Menke A, Brun S, Wamsler C, Zernikow B. Status quo of palliative care in pediatric oncology-a nationwide survey in Germany. J Pain Symptom Manag. 2005;29:156-64.

22. Elo S, Kyngas H. The qualitative content analysis process. J Adv Nurs. 2008; 62:107-15.

23. Elo S, Kääriäinen M, Kanste O, et al. Qualitative content analysis: a focus on trustworthiness. SAGE Open. 2014;4:2158244014522633.

24. Rodriguez KL, Barnato AE, Arnold RM. Perceptions and utilization of palliative care services in acute care hospitals. J Palliat Med. 2007;10:99-110.

25. Hui D, Bruera E. Integrating palliative care into the trajectory of cancer care. Nat Rev Clin Oncol. 2016;13:159-71.

26. Abrahm JL. Integrating palliative care into comprehensive cancer care. J Natl Compr Cancer Netw. 2012;10:1192-8.

27. Bruera E, Hui D. Conceptual models for integrating palliative care at cancer centers. J Palliat Med. 2012;15:1261-9.

28. Glare PA. Early implementation of palliative care can improve patient outcomes. J Natl Compr Cancer Netw. 2013:11:S3-9.

29. Zhi WI, Smith TJ. Early integration of palliative care into oncology: evidence, challenges and barriers. Ann Palliat Med. 2015;4:122-31.

\section{Publisher's Note}

Springer Nature remains neutral with regard to jurisdictional claims in published maps and institutional affiliations.

Ready to submit your research? Choose BMC and benefit from:

- fast, convenient online submission

- thorough peer review by experienced researchers in your field

- rapid publication on acceptance

- support for research data, including large and complex data types

- gold Open Access which fosters wider collaboration and increased citations

- maximum visibility for your research: over $100 \mathrm{M}$ website views per year

At $\mathrm{BMC}$, research is always in progress.

Learn more biomedcentral.com/submissions 